\title{
Moving from fundamental knowledge of kinetics and mechanisms on surfaces to prediction of catalyst performance in reactors. Supporting Information
}

\author{
Christian Reece ${ }^{1}$, and Robert. J. Madix ${ }^{2 *}$ \\ 1. Harvard University, Rowland Institute at Harvard, Cambridge, MA, USA \\ 2. Harvard University, School of Engineering and Applied Science, Cambridge, MA, USA \\ *To whom correspondence should be addressed: rmadix@seas.harvard.edu
}

Throughout this perspective we have made reference to a number of experimental techniques that may or may not be familiar to the readers. For the purpose of providing a reference for the reader we have decided to provide an introduction to both the experimental methodology and the theory behind two of the most discussed techniques: Temperature Programmed Reaction (Desorption), and Temporal Analysis of Products.

\section{Temperature Programmed Reaction/Desorption Spectroscopy}

The two forms of temperature programmed spectroscopy discussed in this perspective are Temperature Programmed Reaction Spectroscopy (TPRS) and Temperature Programmed Desorption (TPD). The experimental setup and analysis of both techniques is the same, with the difference between the two denoting if there has been any underlying reactivity between the adsorbate and the sample. If the adsorbate desorbs with no reaction, it is classified as a TPD experiment. The temperature programmed experiments can be summarised as such: A known amount of a species is adsorbed to the surface of a catalyst, the catalyst is then heated in a linear fashion, and the resulting products are measured as a function of time (or temperature). At this point, it may be best to discuss why it can be favourable to perform a temperature programmed experiment, as opposed to an isothermal experiment where the temperature is fixed at constant value. First, in the equivalent isothermal experiment (where the temperature is fixed) must be performed within a range where the temperature is high enough that some conversion can be measured, but not too high that during the warm-up time a significant amount of the reagent has already been converted or desorbed. Instead, by first adsorbing the species at a temperature far below the adsorption or reaction temperature, and then linearly heating and watching the evolution of the products as a function of temperature, the reaction can be watched from a consistent start point (initial coverage) to a consistent end point (no further reaction, or zero coverage). However, the caveats of performing temperature programmed experiments are that the temperature ramp must be fast enough that the rate of desorption is measurable, but not too fast that the concentration of the adsorbent changes significantly between measured points.

For a simple case of a unreversible first order reaction, $(\mathrm{A} \rightarrow \mathrm{B})$ we can consider the standard Arrhenius form of the rate equation, in which the rate of reaction (the change in concentration over time) is expressed as such:

$$
\frac{d\left[\mathrm{~A}^{*}\right]}{d t}=-A \exp \left(\frac{-E_{a}}{R T}\right)\left[\mathrm{A}^{*}\right]
$$


where $\left[\mathrm{A}^{*}\right]$ is the concentration of the adsorbed species $\mathrm{A}^{*}, E_{a}$ is the activation energy $(\mathrm{kJ} / \mathrm{mol}), T$ is the temperature $(\mathrm{K})$, and $A$ the pre-exponential factor $\left(\mathrm{s}^{-1}\right)$. The temperature during these experiments is controlled programmatically so that the temperature varies at a constant rate $\beta(\mathrm{K} / \mathrm{s})$ :

$$
\beta=\frac{d T}{d t}=\text { constant }
$$

In the case of linear heating, time and temperature become interchangeable with one another, meaning Equation SA can then be expressed as a function of temperature instead of time.

$$
\frac{d\left[\mathrm{~A}^{*}\right]}{d T}=-\frac{A}{\beta} \exp \left(\frac{-E_{a}}{R T}\right)\left[\mathrm{A}^{*}\right]
$$

Using equation (SC) a simple TPRS experiment can be simulated (Figure SA). The kinetic precision of TPRS experiments is exemplified in Figure SAA, where a difference of $4 \mathrm{~kJ} / \mathrm{mol}$ in activation energy represents a peak shift of $12 \mathrm{~K}$. With differences in peak temperatures be resolvable down to the single kelvin limit in certain conditions, this provides a kinetic resolution of $<1 \mathrm{~kJ} / \mathrm{mol}$. The peak temperature is not the only kinetically identifying component, the shape of the peak provides information on the reaction too. For a second order reaction, for example a recombination of two species to desorb off the surface, equation SC can be modified to represent the change in chemistry.

$$
\frac{d\left[\mathrm{~A}^{*}\right]}{d T}=-\frac{A}{\beta} \exp \left(\frac{-E_{a}}{R T}\right)\left[\mathrm{A}^{*}\right]^{2}
$$

The effect of reaction order is demonstrated in Figure SAB, where the first order peak is non-symmetric around the peak temperature, whereas the second order peak is symmetric. This simple qualitative test can be used to identify if a process is unimolecular or bimolecular.
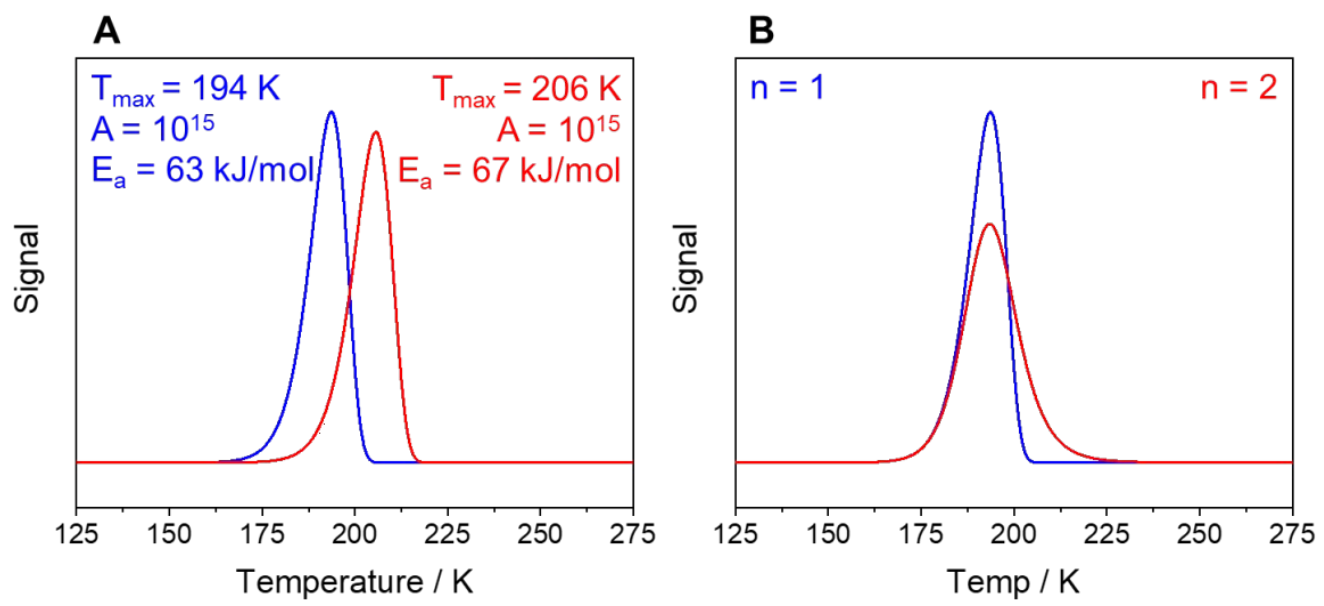

Figure S1. Simulated TPRS experiments (A) Where a species A* goes under first order desorption from the surface with a pre-exponential factor of $10^{15} \mathrm{~s}^{-1}$, activation energy of 63 (blue) and 67 (red) $\mathrm{kJ} / \mathrm{mol}$ respectively, and a heating rate of $5 \mathrm{~K} / \mathrm{s}$. A difference in peak temperature of $12 \mathrm{~K}$ arises from a $4 \mathrm{~kJ} / \mathrm{mol}$ change. (B) Where species $A^{*}$ desorbs from the surface via first $(\mathrm{n}=1)$ or second $(\mathrm{n}=2)$ order kinetics, pre-exponential factor of $10^{15} \mathrm{~s}^{-1}$, activation energy of $63 \mathrm{~kJ} / \mathrm{mol}$, heating rate of $5 \mathrm{~K} / \mathrm{s}$. 
While there are methods of determining kinetic coefficients from single heating rate TPRS profiles (discussed in the main text), the "gold standard" is considered to be a multiple heating rate experiment. In which the TPRS experiment is performed at multiple heating rates, and the peak temperatures recorded. The theory behind these experiments was first proposed by Kissenger ${ }^{1}$ and applied to TPRS spectroscopy by Falconer and Madix ${ }^{2}$ and can be described as follows. At the maximum rate (or the peak temperature) the difference in the rate of reaction is zero:

$$
\frac{d^{2}\left[\mathrm{~A}^{*}\right]}{d t^{2}}=\left[\frac{E_{a} \beta}{R T_{\max }^{2}}+A f^{\prime}\left(\left[\mathrm{A}^{*}\right]_{\max }\right) \exp \left(\frac{-E_{a}}{R T_{\max }}\right)\right]\left(\frac{d\left[\mathrm{~A}^{*}\right]}{d t}\right)_{\max }=0
$$

where max indicates it's at the rate maximum, and $f^{\prime}\left(\left[\mathrm{A}^{*}\right]_{\max }\right)=d f\left(\left[\mathrm{~A}^{*}\right]\right) / d\left[\mathrm{~A}^{*}\right]$. For reaction of $n$th order equation SE can be simplified.

$$
\ln \left(\frac{\beta}{T_{\max }^{2}}\right)=\ln \left(\frac{A R}{E_{a}} n\left[\mathrm{~A}^{*}\right]^{n-1}\right)-\frac{E_{a}}{R T_{\max }}
$$

Therefore, for a first order reaction, a plot of $\ln \left(\frac{\beta}{T_{\max }^{2}}\right)$ vs $-\frac{1}{T_{\max }}$ will give a gradient of $\frac{E_{a}}{R}$, giving an activation energy, and an intercept of $\ln \left(\frac{A R}{E_{a}}\right)$ giving the pre-exponential factor. The benefit of using this technique is that the intrinsic kinetics of a unimolecular (first order) step can be measured without any pre-required knowledge of the surface coverages.

\section{Temporal Analysis of Products: A Knudsen flow pulse reactor}

Temporal Analysis of Products (TAP) plays a prominent role in the measurement of kinetic parameters over high surface area catalytic materials. Developed by John Gleaves ${ }^{3}$ the experimental design has been refined over multiple ${ }^{4}$ generations. ${ }^{5}$ The TAP experiment is conceptually very simple, but in practically quiet difficult. The TAP experiment can be summarised as such: A microreactor packed with a thin layer of catalyst between two layers of inert packing material is evacuated to UHV, then a short, sharp pulse of reactant gas mixed with inert ( $100 \mu \mathrm{s}, 10^{-9}$ moles, $10^{15}$ molecules $)$ is sent into the reactor entrance via a pulse valve, the reactant gas then propagates through the bed via Knudsen diffusion, and the exit flux is measured via mass spectrometry (Figure 8). The further development of the TAP technique was also accompanied by an increased understanding of the theory pioneered by Yablonsky. ${ }^{4}$ The benefits of the TAP technique are that it makes it possible to precise probe the kinetics of gas and surface reactions over powdered catalysts at both the sub-millisecond level and over extended timescales. In a single pulse experiment, the exit fluxes measured for the reactants and products can be compared with that of an inert species, with any differences in shape arising solely due to the kinetics of the reaction, due to the precisely defined Knudsen diffusion through the bed (see proceeding section). While individual pulses are a powerful tool for probing kinetics, it's when pulses are performed sequentially that the level of detail that a deeper understand of the material can be garnered. A single pulse of a sufficiently small size (typically on the range of $10^{13}$ to $10^{16}$ molecules) does not perturb the catalyst state by any significant amount, affording a "kinetic snapshot" of the surface at that specific point. However, by repeatedly pulsing it is possible to perform chemical calculus ${ }^{5,6}$ where the surface can be modified by a series of small insignificant changes. By measuring the kinetic coefficients at each snapshot, and then comparing how those coefficients change as a function of induced surface modifications affords a level of kinetic insight not feasible with other experimental means. 
The theory behind the TAP experiment can be described by a series of partial differential equations (PDEs). The transport through the reactor for a gas A adsorbing to the surface via the reaction $\mathrm{A}+{ }^{*} \rightleftharpoons$ $\mathrm{A}^{*}$, with * representing an empty adsorption site, can be described by the following series of differential equations:

$$
\varepsilon_{b} \frac{d[A]}{d t}=D_{e} \frac{d^{2}[A]}{d z^{2}}-S_{v}\left(1-\varepsilon_{b}\right)\left(k_{a}[A]\left[{ }^{*}\right]-k_{d}\left[A^{*}\right]\right)
$$

Where $[\mathrm{A}]$ is the concentration of species $\mathrm{A}\left(\operatorname{molecules} / \mathrm{cm}^{3}\right), \varepsilon_{b}$ is the fractional voidage of the reactor, $z$ is the axial coordinate $(\mathrm{cm}), D_{e}$ is the Knudsen diffusivity $\left(\mathrm{cm}^{2} / \mathrm{s}\right), S_{v}$ is the surface area of catalyst per volume of catalyst $\left(\mathrm{cm}^{-1}\right), k_{a}$ is the adsorption rate constant $\left(\mathrm{cm}^{3} / \mathrm{s}\right)$ and $k_{d}$ is the desorption constant ( $\mathrm{s}^{-1}$ for a first order desorption, $\mathrm{cm}^{2} / \mathrm{s}$ for second order desorption). Any surface reactions can be described using a simple mean field differential equation:

$$
\frac{d\left[A^{*}\right]}{d t}=k_{a}[A]\left[{ }^{*}\right]-k_{d}\left[A^{*}\right]
$$

For nonreactive gases, or during the inert zones, $k_{a}$ and $k_{d}$ are set to 0 . By applying the initial condition of a delta function pulse at the reactor inlet at $\mathrm{t}=0$

$$
\left.\frac{d[A]}{d z}\right|_{z=0, t=0}=\delta \frac{N_{p A}}{\varepsilon_{b} A}
$$

with $N_{p A}$ being the number of molecules in the inlet pulse. boundary conditions are zero flux at the reactor entrance at $\mathrm{t}>0$ (as the pulse valve is closed), and a zero concentration at the reactor exit (as the system is attached to a vacuum chamber).

$$
\begin{aligned}
& \left.\frac{d[A]}{d z}\right|_{z=0, t>0}=0 \\
& \left.\frac{d[A]}{d z}\right|_{z=0}=\delta \frac{N_{p A}}{\varepsilon_{b} A}
\end{aligned}
$$

At the boundary between the zones (inert and reactant) there is a conservation of flux and concentration

$$
\begin{gathered}
{[A]^{I}=[A]^{I I}} \\
D_{e} \frac{d^{2}[A]^{I}}{d z^{2}}=D_{e} \frac{I I \frac{d^{2}[A]^{I I}}{d z^{2}}}{}
\end{gathered}
$$

Where I and II represent zones one and two respectively. By solving these series of PDEs analytically ${ }^{7-10}$ or numerically ${ }^{11}$ it is possible to recreate TAP pulses to a high precision (Figure S2). 


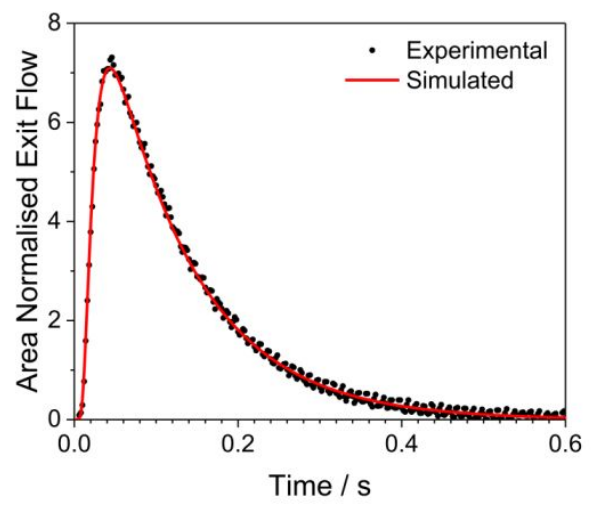

Figure S2. Experimentally measured exit flux (flow) compared against the simulated exit flux using the PDE described in equation S7 for a pulse of Argon through a packed microreactor at $423 \mathrm{~K}$. Reprinted with permission from ref 12 .

\section{Supplemental Figures}
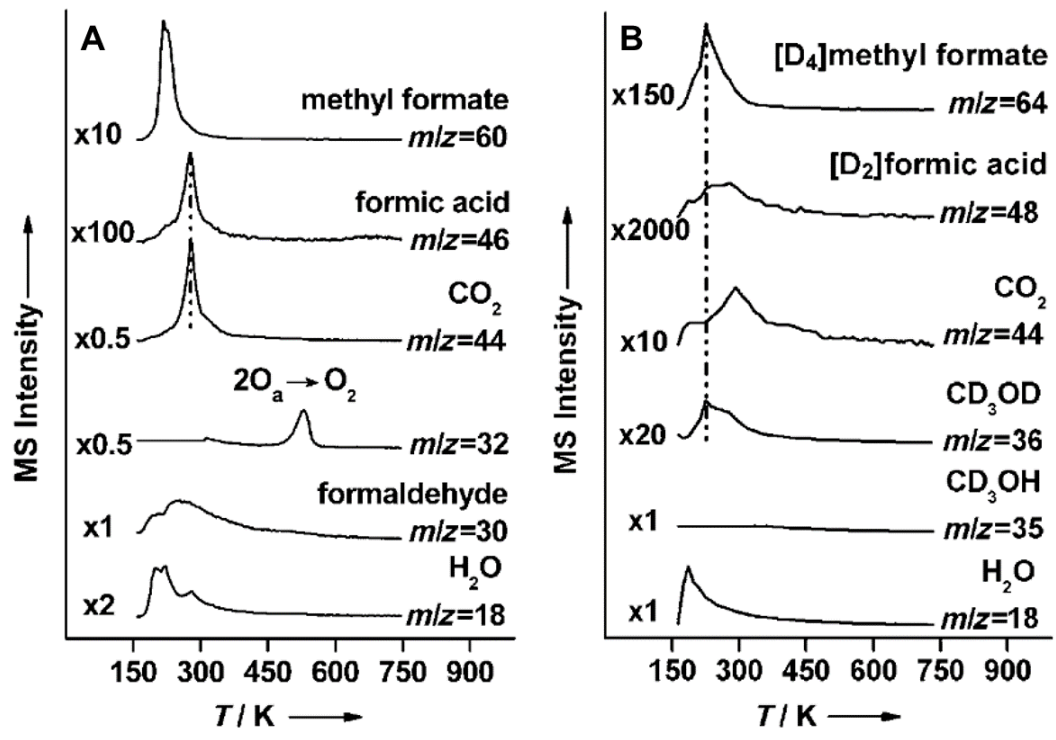

Figure S3. Product evolution resulting from dosing methanol onto $\mathrm{O}$ atoms preadsorbed on an $\mathrm{Au}(111)$ single crystal surface using (A) $\mathrm{CH}_{3} \mathrm{OH}$ at $0.2 \mathrm{ML}$ precoverage, (B) $\mathrm{CD}_{3} \mathrm{OH}$ at $0.05 \mathrm{ML}$ precoverage. Due to the initially high $\mathrm{O}$ coverage, substantial formation of secondary oxidation species (formate) and its products is observed. The $15 \mathrm{~K}$ difference in desorption temperature between $\mathrm{d}_{0}$-methyl formate (A) and $\mathrm{d}_{4}$-methyl formate (B), combined with the concomitant release of $\mathrm{CD}_{3} \mathrm{OH}$ on release of $\mathrm{d}_{4^{-}}$ methyl formate indicates that the rate limiting step for methanol self-coupling is the cleavage of the $\mathrm{C}-\mathrm{H}$ bond in adsorbed methoxy. Adapted and reprinted with permission from ref 13. 
Table S1. Elementary steps for the extended methanol self-coupling network calculated by Reocreux et al with their corresponding activation energies. ${ }^{14}$

\begin{tabular}{|c|c|c|c|c|c|c|}
\hline & & & \multicolumn{2}{|c|}{$\begin{array}{l}\text { Pre-Exponent } \\
\left(\mathrm{s}^{-1} / \mathrm{cm}^{2} / \mathrm{s}\right)\end{array}$} & \multicolumn{2}{|c|}{$\begin{array}{c}\text { Activation Energy } \\
(\mathrm{kJ} / \mathrm{mol})\end{array}$} \\
\hline \multicolumn{3}{|c|}{ Elementary Reaction Step } & Forward & Reverse & Forward & Reverse \\
\hline $\mathrm{CH}_{3} \mathrm{OH}$ & $\rightleftharpoons$ & $\mathrm{CH}_{3} \mathrm{OH}^{*}$ & - & $6.70 \times 10^{14}$ & 0.00 & 42.46 \\
\hline $\mathrm{CH}_{2} \mathrm{O}$ & $\rightleftharpoons$ & $\mathrm{CH}_{2} \mathrm{O}^{*}$ & - & $1.39 \times 10^{15}$ & 0.00 & 30.88 \\
\hline $\mathrm{HCOOCH}_{3}$ & $\rightleftharpoons$ & $\mathrm{HCOOCH}^{*}$ & - & $6.67 \times 10^{15}$ & 0.00 & 40.53 \\
\hline $\mathrm{CO}_{2}$ & $\rightleftharpoons$ & $\mathrm{CO}_{2}^{*}$ & - & $1.74 \times 10^{16}$ & 0.00 & 20.26 \\
\hline $\mathrm{H}_{2}$ & $\rightleftharpoons$ & $2 \mathrm{H}^{*}$ & - & - & 61.75 & 63.68 \\
\hline $\mathrm{H}_{2} \mathrm{O}$ & $\rightleftharpoons$ & $\mathrm{H}_{2} \mathrm{O}^{*}$ & - & $1.13 \times 10^{14}$ & 0.00 & 28.95 \\
\hline $\mathrm{CH}_{3} \mathrm{OH}^{*}$ & $\rightleftharpoons$ & $\mathrm{CH}_{3} \mathrm{O}^{*+}+\mathrm{H}^{*}$ & $1.17 \times 10^{11}$ & $1.61 \times 10^{-2}$ & 164.03 & 51.14 \\
\hline $\mathrm{CH}_{3} \mathrm{OH}^{*}+\mathrm{O}^{*}$ & $\rightleftharpoons$ & $\mathrm{CH}_{3} \mathrm{O}^{*+} \mathrm{OH}^{*}$ & $2.45 \times 10^{-5}$ & $3.28 \times 10^{3}$ & 25.09 & 25.09 \\
\hline $\mathrm{CH}_{3} \mathrm{OH}^{*}+\mathrm{OH}^{*}$ & $\rightleftharpoons$ & $\mathrm{CH}_{3} \mathrm{O}^{*}+\mathrm{H}_{2} \mathrm{O}^{*}$ & $3.81 \times 10^{-5}$ & $1.94 \times 10^{-4}$ & 2.89 & 0.00 \\
\hline $\mathrm{CH}_{3} \mathrm{O}$ & $\rightleftharpoons$ & $\mathrm{CH}_{2} \mathrm{O}^{*+\mathrm{H}^{*}}$ & $6.77 \times 10^{12}$ & $2.72 \times 10^{-4}$ & 73.33 & 39.56 \\
\hline $\mathrm{CH}_{3} \mathrm{O}+\mathrm{O}$ & $\rightleftharpoons$ & $\mathrm{CH}_{2} \mathrm{O}^{*}+\mathrm{OH}^{*}$ & $2.90 \times 10^{-3}$ & $1.16 \times 10^{-4}$ & 41.49 & 149.56 \\
\hline $\mathrm{CH}_{3} \mathrm{O}+\mathrm{OH}$ & $\rightleftharpoons$ & $\mathrm{CH}_{2} \mathrm{O}^{*}+\mathrm{H} 2 \mathrm{O}^{*}$ & $4.49 \times 10^{-3}$ & $6.87 \times 10^{-6}$ & 67.54 & 184.30 \\
\hline $\mathrm{CH}_{3} \mathrm{O}^{*}+\mathrm{CH}_{3} \mathrm{O}^{*}$ & $\rightleftharpoons$ & $\mathrm{CH}_{3} \mathrm{OH}^{*}+\mathrm{CH}_{2} \mathrm{O}^{*}$ & $5.10 \times 10^{-3}$ & $1.52 \times 10^{-6}$ & 63.68 & 172.72 \\
\hline $\mathrm{CH}_{2} \mathrm{O}^{*}+\mathrm{CH}_{3} \mathrm{O}^{*}$ & $\rightleftharpoons$ & $\mathrm{H}_{2} \mathrm{COOCH}_{3} *$ & $1.72 \times 10^{-2}$ & $1.25 \times 10^{14}$ & 23.16 & 80.09 \\
\hline $\mathrm{CH}_{2} \mathrm{O}^{*}+\mathrm{O}^{*}$ & $\rightleftharpoons$ & $\mathrm{H}_{2} \mathrm{COO}^{*}$ & $1.35 \times 10^{-4}$ & $5.59 \times 10^{12}$ & 9.65 & 52.10 \\
\hline $\mathrm{CH}_{2} \mathrm{O}^{*}+\mathrm{OH}^{*}$ & $\rightleftharpoons$ & $\mathrm{H}_{2} \mathrm{COOH}^{*}$ & $2.25 \times 10^{-4}$ & $1.72 \times 10^{12}$ & 5.79 & 58.86 \\
\hline $\mathrm{H}_{2} \mathrm{COOCH}_{3} *$ & $\rightleftharpoons$ & $\mathrm{HCOOCH}_{3} *+\mathrm{H}^{*}$ & $2.02 \times 10^{12}$ & $5.71 \times 10^{-5}$ & 51.14 & 114.82 \\
\hline $\mathrm{H}_{2} \mathrm{COOCH}_{3}{ }^{*}+\mathrm{O}^{*}$ & $\rightleftharpoons$ & $\mathrm{HCOOCH}_{3}{ }^{*}+\mathrm{OH}^{*}$ & $1.74 \times 10^{-3}$ & $4.92 \times 10^{-5}$ & 20.26 & 227.72 \\
\hline $\mathrm{H}_{2} \mathrm{COOCH}_{3} *+\mathrm{OH}^{*}$ & $\rightleftharpoons$ & $\mathrm{HCOOCH}_{3} *+\mathrm{H}_{2} \mathrm{O} *$ & $2.44 \times 10^{-3}$ & $2.59 \times 10^{-6}$ & 68.51 & 253.77 \\
\hline $\mathrm{H}_{2} \mathrm{COO}^{*}$ & $\rightleftharpoons$ & $\mathrm{HCOO}^{*+\mathrm{H}^{*}}$ & $4.59 \times 10^{12}$ & $1.57 \times 10^{-3}$ & 27.02 & 129.30 \\
\hline $\mathrm{H}_{2} \mathrm{COO}^{*+\mathrm{O}^{*}}$ & $\rightleftharpoons$ & $\mathrm{HCOO}^{*}+\mathrm{OH}^{*}$ & $2.32 \times 10^{-3}$ & $8.06 \times 10^{-4}$ & 11.58 & 289.47 \\
\hline $\mathrm{H}_{2} \mathrm{COO}^{*}+\mathrm{OH}^{*}$ & $\rightleftharpoons$ & $\mathrm{HCOO}^{*+\mathrm{H}_{2}} \mathrm{O}^{*}$ & $3.68 \times 10^{-3}$ & $4.90 \times 10^{-5}$ & 19.30 & 304.91 \\
\hline $\mathrm{HCOO}^{*}$ & $\rightleftharpoons$ & HCOOm* & $6.07 \times 10^{13}$ & $2.13 \times 10^{13}$ & 75.26 & 12.54 \\
\hline HCOOm* & $\rightleftharpoons$ & $\mathrm{H}^{*}$ & $3.08 \times 10^{12}$ & $1.23 \times 10^{-2}$ & 4.82 & 95.53 \\
\hline $\mathrm{HCOO}^{*}+\mathrm{O}^{*}$ & $\rightleftharpoons$ & $\mathrm{OH}^{*}$ & $2.60 \times 10^{-3}$ & $9.88 \times 10^{-3}$ & 90.70 & 240.26 \\
\hline $\mathrm{HCOO}^{*}+\mathrm{OH}^{*}$ & $\rightleftharpoons$ & $\mathrm{H}_{2} \mathrm{O}^{*}$ & $4.57 \times 10^{-3}$ & $6.56 \times 10^{-4}$ & 113.86 & 250.87 \\
\hline $\mathrm{H}_{2} \mathrm{O}^{*}$ & $\rightleftharpoons$ & $\mathrm{H}^{*}+\mathrm{OH}^{*}$ & $5.64 \times 10^{11}$ & $1.51 \times 10^{-2}$ & 173.68 & 54.03 \\
\hline $\mathrm{OH}^{*}$ & $\rightleftharpoons$ & $\mathrm{O}^{*+\mathrm{H}^{*}}$ & $3.84 \times 10^{12}$ & $3.88 \times 10^{-3}$ & 189.12 & 57.89 \\
\hline $\mathrm{OH}^{*}+\mathrm{OH}^{*}$ & $\rightleftharpoons$ & $\mathrm{H}_{2} \mathrm{O}^{*}+\mathrm{O}^{*}$ & $3.53 \times 10^{-3}$ & $1.36 \times 10^{-4}$ & 4.82 & 27.98 \\
\hline
\end{tabular}

* Indicates species is adsorbed to surface.

\section{References}

(1) Kissinger, H. E. Reaction Kinetics in Differential Thermal Analysis. Anal. Chem. 1957, 29 (11), 1702-1706.

(2) Falconer, J. L.; Madix, R. J. Flash Desorption Activation Energies: DCOOH Decomposition and CO Desorption from Ni (110). Surf. Sci. 1975, 48 (2), 393-405.

(3) Gleaves, J. T.; Ebner, J. R.; Kuechler, T. C. Temporal Analysis of Products (TAP) - A Unique Catalyst Evaluation System with Submillisecond Time Resolution. Catal. Rev. 1988, $30(1), 49-116$.

(4) Gleaves, J. T.; Yablonskii, G. S.; Phanawadee, P.; Schuurman, Y. TAP-2: An Interrogative Kinetics Approach. Appl. Catal. A Gen. 1997, 160 (1), 55-88.

(5) Gleaves, J. T.; Yablonsky, G.; Zheng, X.; Fushimi, R.; Mills, P. L. Temporal Analysis of Products (TAP)-Recent Advances in Technology for Kinetic Analysis of Multi-Component Catalysts. J. Mol. Catal. A Chem. 2010, 315 (2), 108-134.

(6) Shekhtman, S. O.; Goguet, A.; Burch, R.; Hardacre, C.; Maguire, N. CO Multipulse TAP Studies of $2 \% \mathrm{Pt} / \mathrm{CeO} 2$ Catalyst: Influence of Catalyst Pretreatment and Temperature on the 
Number of Active Sites Observed. J. Catal. 2008, 253 (2), 303-311.

(7) Constales, D.; Yablonsky, G. S.; Marin, G. B.; Gleaves, J. T. Multi-Zone Tap-Reactors Theory and Application: I. The Global Transfer Matrix Equation. Chem. Eng. Sci. 2001, 56 (1), 133149.

(8) Constales, D.; Yablonsky, G. S.; Marin, G. B.; Gleaves, J. T. Multi-Zone TAP-Reactors Theory and Application: II. The Three-Dimensional Theory. Chem. Eng. Sci. 2001, 56 (5), 1913-1923.

(9) Constales, D.; Yablonsky, G. S.; Marin, G. B.; Gleaves, J. T. Multi-Zone TAP-Reactors Theory and Application. III Multi-Response Theory and Criteria of Instantaneousness. Chem. Eng. Sci. 2004, 59 (17), 3725-3736.

(10) Constales, D.; Shekhtman, S. O.; Yablonsky, G. S.; Marin, G. B.; Gleaves, J. T. Multi-Zone TAP-Reactors Theory and Application IV. Ideal and Non-Ideal Boundary Conditions. Chem. Eng. Sci. 2006, 61 (6), 1878-1891.

(11) Roelant, R. Mathematical Determination of Reaction Networks from Transient Kinetic Experiments, Universitet Ghent, 2011.

(12) Reece, C.; Redekop, E. A.; Karakalos, S.; Friend, C. M.; Madix, R. J. Crossing the Great Divide between Single-Crystal Reactivity and Actual Catalyst Selectivity with Pressure Transients. Nat. Catal. 2018, 1 (11), 852-859.

(13) Xu, B.; Liu, X.; Haubrich, J.; Madix, R. J.; Friend, C. M. Selectivity Control in Gold-Mediated Esterification of Methanol. Angew. Chemie - Int. Ed. 2009, 48 (23), 4206-4209.

(14) Réocreux, R.; Fampiou, I.; Stamatakis, M. The Role of Oxygenated Species in the Catalytic Self-Coupling of MeOH on O Pre-Covered Au(111). Faraday Discuss. 2020. 